Article

\title{
High performance Pd catalysts supported on bimodal mesopore silica for the catalytic oxidation of toluene
}

\author{
Nanli Qiao, Yang Li, Na Li, Xin Zhang, Jie Cheng*, Zhengping Hao \\ Research Center for Eco-Environmental Sciences, Chinese Academy of Sciences, Beijing 100085, China
}

\section{A R T I C L E I N F O}

Article history:

Received 16 March 2015

Accepted 11 June 2015

Published 20 October 2015

Keywords:

Bimodal mesoporous silica

Pore structure

Catalytic oxidation

Toluene

Palladium

\begin{abstract}
A B S T R A C T
A series of bimodal mesoporous silica (BMS- $x$ )-supported Pd catalysts were successfully prepared by a facile sol-gel approach, followed by an impregnation method. The synthesized catalysts were characterized by several analytical techniques and the oxidation of toluene was used to evaluate their catalytic performance. Textural analysis showed that all samples had high surface areas $\left(\sim 1000 \mathrm{~m}^{2} / \mathrm{g}\right)$, large pore volumes $\left(\sim 1.2 \mathrm{~cm}^{3} / \mathrm{g}\right)$ and uniform mesopore size $(\sim 2.6 \mathrm{~nm})$. Defining the level of ammonia solution to within a certain range resulted in the catalysts possessing a typical bimodal mesoporous structure with an intraparticle framework mesopore and an interparticle textural mesopore (18-40 nm). Transmission electron microscopy observations and CO chemisorption results revealed that this unique bimodal mesoporous structure helped to decrease the particle size of Pd nanoparticles and could further enhance their dispersion. Activity tests revealed the Pd/BMS-5-Pd/BMS-20 catalysts with a bimodal mesopore structure possessed superior catalytic performance for the oxidation of toluene compared to Pd/BMS-30 with a unimodal mesopore structure. More importantly, compared with the Pd/MCM-41 and Pd/MCM-48 catalysts, Pd/BMS-15 had improved hydrothermal stability and catalytic performance at a high gas hourly space velocity of $70000 \mathrm{~h}^{-1}$. These results indicate the potential application of the catalysts for the elimination of volatile organic compounds.
\end{abstract}

(C) 2015, Dalian Institute of Chemical Physics, Chinese Academy of Sciences. Published by Elsevier B.V. All rights reserved.

\section{Introduction}

Volatile organic compounds (VOCs), an important class of air pollutants emitted from many industrial processes and transportation activities [1,2], are harmful to human health and the environment because of their toxic, carcinogenic, mutagenic, and teratogenetic nature [3-5]. Several technologies are currently used to eliminate VOCs from the air. Among them, catalytic oxidation has been recognized as one of the most promising methods to address this matter [6]. A key issue in catalytic oxidation is the synthesis of high-performance cata- lysts. Supported noble metal (e.g., Pd, Pt and Rh) and transition metal oxide catalysts have been extensively studied with regard to VOC oxidation.

Pd-based catalysts are abundantly used because of their superior activity, high thermal stability and hydrothermal tolerance [7,8]. Catalyst support design is an important factor when optimizing the performance of Pd-based catalysts. The morphology and textural characteristics of the support have a direct impact on the size, shape and loading level of the Pd particles supported on the catalyst [9]. In addition, the pore size of the support material is an important factor to consider when

\footnotetext{
* Corresponding author. Tel/Fax: +86-10-62843688; E-mail: jiecheng@rcees.ac.cn

This work was supported by the National Natural Science Foundation of China $(21337003,21477149)$ and the Strategic Priority Research Program of the Chinese Academy of Sciences (XDB05050200).

DOI: 10.1016/S1872-2067(15)60924-X | http://www.sciencedirect.com/science/journal/18722067 | Chin. J. Catal., Vol. 36, No. 10, October 2015
} 
designing a catalyst as this property has a direct impact on the diffusion of the reactant/product molecules. Since the discovery of the mesoporous M41 family materials, especially MCM-41 and MCM-48, there has been a wealth of research using such materials as catalyst supports because of the ability to specifically tailor the physico-chemcial and textural properties [10-13]. However, the pore size of these materials is often only several nanometers (2-5 nm), which dramatically limits ingress and diffusion of guest molecules to the active sites located inside the pore and resulting in low catalytic activity.

In recent years, solid materials with bimodal mesoporous distributions have received considerable attention [14-17]. Compared with traditional mesoporous M41s possessing a single pore distribution, the secondary pores in bimodal porous structure materials offer greatly improved access for molecules to diffuse into with less resistance $[18,19]$. At the same time, the advantage of bimodal porous materials has also been confirmed from simulations in the Knudsen diffusion regime, whereby molecules are able to ingress/egress mesopores but experience an attendant diffusion limitation [20-22]. The superiority of bimodal porous materials has been demonstrated in the areas of Fischer-Tropsch synthesis [23], photocatalysis [24], methane combustion [25] and CO preferential oxidation [26]; however, to the best of our knowledge, there are no reports linking the benefits of bimodal porous materials to catalytic oxidation of VOCs.

In this study, we synthesized a series of bimodal mesoporous silica materials (BMS- $x$ ) by a facile sol-gel approach. Thereafter, Pd/BMS- $x$ catalysts were prepared via an impregnation method. Toluene was chosen as the VOC probe molecule because of its presence in industrial and automotive emissions, in addition to its high toxicity to human health. The primary purpose of the study was to investigate the relation between catalytic activity and the textural properties of the supports. Characterization was performed by X-ray diffraction (XRD), $\mathrm{N}_{2}$ adsorption-desorption, field-emission scanning electron microscopy (FE-SEM), transmission electron microscopy (TEM) and $\mathrm{CO}$ chemisorption.

\section{Experimental}

\subsection{Catalyst preparation}

The synthesis procedure has been reported elsewhere $[27,28]$. First, $2.1 \mathrm{~g}$ of cetyltrimethylammonium bromide (CTAB) was dissolved in $40 \mathrm{~mL}$ of deionized water, with stirring at room temperature. After the solution became clear, 7 $\mathrm{mL}$ of tetraethyl orthosilicate (TEOS) was added dropwise to obtain a mixed solution. After $1 \mathrm{~h}$, a desired amount of $2 \mathrm{~mol} / \mathrm{L}$ ammonia solution was added to form a solution with a varying $\mathrm{pH}$. The solution became progressively viscous and finally developed into a white gel, after which it was kept under static conditions for $5 \mathrm{~h}$ at room temperature for further silica condensation. Subsequently, the gel mixture was filtered and washed repeatedly with deionized water until a neutral $\mathrm{pH}$ was obtained. The white product was dried at $70{ }^{\circ} \mathrm{C}$ overnight to remove moisture and calcined at $550{ }^{\circ} \mathrm{C}$ for $6 \mathrm{~h}$ to remove the surfactant $\mathrm{CTAB}$ at a heating rate of $3{ }^{\circ} \mathrm{C} / \mathrm{min}$. To study the effect of aqueous ammonia on the structure of synthetic silica materials, the same experiment was repeated with varying quantities (5-30 mL) of $2 \mathrm{~mol} / \mathrm{L}$ aqueous ammonia. The samples were referred to as BMS-5, BMS-10, BMS-15, BMS-20 and BMS-30, wherein the numeric values refer to the amount (in $\mathrm{mL}$ ) of $2 \mathrm{~mol} / \mathrm{L}$ aqueous ammonia. For the purpose of comparison, MCM-41 and MCM-48 supports were synthesized according to procedures described elsewhere [11].

Pd-supported catalysts with a Pd loading of $0.5 \mathrm{wt} \%$ were prepared via an impregnation method with an aqueous solution of $\mathrm{PdCl}_{2}$. The impregnated solids were dried at $100{ }^{\circ} \mathrm{C}$ overnight and calcined at $500{ }^{\circ} \mathrm{C}$ for $3 \mathrm{~h}$ (heating rate of 3 ${ }^{\circ} \mathrm{C} / \mathrm{min}$ ). Finally, the catalysts were reduced in a pure $\mathrm{H}_{2}$ stream with a $50 \mathrm{~mL} / \mathrm{min}$ flow rate at $400{ }^{\circ} \mathrm{C}$ for $2 \mathrm{~h}$.

\subsection{Catalyst characterization}

XRD patterns were recorded on a PANalytical X'Pert PRO powder diffraction system using $\mathrm{Cu} K \alpha$ radiation $(\lambda=0.15418$ $\mathrm{nm}$ ) in the $2 \theta$ range of $0.7^{\circ}-5^{\circ}$ (scanning rate of $0.5^{\circ} / \mathrm{min}$ ) and $10^{\circ}-80^{\circ}$ (scanning rate $4^{\circ} / \mathrm{min}$ ), respectively. The textural properties of the samples were analyzed from $\mathrm{N}_{2}$ adsorption-desorption isotherms using a Micromeritics ASAP 2020 gas absorption analyzer. The specific surface area was calculated with the Brunauer-Emmett-Teller (BET) method and the pore volume and pore size distribution were estimated from the Barrett-Joyner-Halenda (BJH) model. FE-SEM micrographs were taken on a Hitachi S-4800 microscope. TEM micrographs were recorded on a Hitachi $\mathrm{H}-7500$ microscope operating at an accelerating voltage of $80 \mathrm{kv}$. The exact Pd loading in all synthesized samples was analyzed by inductively coupled plasma optical emission spectroscopy (ICP-OES) on a Perkin Elmer OPTIMA 8300. Pd dispersion of catalysts was determined by CO chemisorption using a dynamic pulse method on a Micromeritics, AutoChem 2920. The samples (50 mg, 40-60 mesh) were reduced at $300{ }^{\circ} \mathrm{C}$ for $30 \mathrm{~min}$ in $5 \% \mathrm{H}_{2} / \mathrm{Ar}(50$ $\mathrm{mL} / \mathrm{min})$, followed by flushing in $\mathrm{He}(50 \mathrm{~mL} / \mathrm{min})$ for $30 \mathrm{~min}$. After cooling to room temperature under a He flow, a pulse of $5 \% \mathrm{CO} / \mathrm{He}$ were introduced to the catalyst.

\subsection{Catalytic activity test}

The activity tests of all catalysts were evaluated using a continuous-flow fixed-bed stainless steel reactor ( $6 \mathrm{~mm}$ i.d.) under atmospheric pressure. Each run contained a specific volume of catalysts in the form of 40-60 mesh particles. To create the stream containing toluene, one stream of pure air was passed through a boat-shaped saturator in an ice-bath to generate a mixed gas containing toluene of high concentration, which was then further diluted by another stream of pure air prior to reaching the catalyst bed. The total flow rate was set to 350 $\mathrm{mL} / \mathrm{min}$ with a concentration of ca. $1000 \mathrm{ppm}$ by adjusting the two flow rates. The reaction temperature was controlled by a tubular electric furnace and the temperature of the catalyst bed was monitored automatically by E-type thermocouples. In each test, the reaction bed temperature was raised to $80{ }^{\circ} \mathrm{C}$ with the 
stream passing and the catalyst was pretreated in the reactant mixture flow for $1 \mathrm{~h}$. Thereafter the reaction bed temperature was increased to the next desired temperature and stabilized for $30 \mathrm{~min}$. The reactants and reaction products were monitored on-line using an Aglient 6820 gas chromatograph (GC), equipped with a TCD (TDX-01) column and a FID (AB-GASPRO capillary column). The stability tests of the catalysts were performed under similar conditions as the activities evaluation. In each run, the catalyst bed was first heated to a desired temperature, which was maintained for $\sim 60 \mathrm{~h}$. Regarding water vapor introduction, 11 vol\% of $\mathrm{H}_{2} \mathrm{O}$ was introduced by passing the feed stream through a water saturator at room temperature.

\section{Results and discussion}

\subsection{Textural properties of synthesized catalyst}

Figure 1(a) displays the small-angle powder XRD diffractograms of all synthesized catalysts, which provide information on the long-range ordering of the mesopores. As shown in Fig $1(a)$, all samples possessed a similar strong and broad diffraction peak at $\sim 2.0^{\circ}$. This can be indexed as the (100) reflection on the basis of the existence of a MCM-41-like hexagonal cell [29], indicating the presence of uniform mesoporosity on all catalyst supports. Wide-angle XRD $\left(2 \theta=10^{\circ}-90^{\circ}\right)$ measure- ments were performed and the diffractograms of all synthesized catalysts are shown in Fig. 1(b). Broad diffraction peaks at $2 \theta$ at $\sim 22^{\circ}$ can be observed in all samples, which are attributed to amorphous silica. No $\mathrm{Pd}$ species $\left(\mathrm{Pd}^{0}, \mathrm{PdO}\right)$ were observed in any samples, indicating that the Pd species were smaller and highly dispersed [30].

The porous structure and specific surface area of the catalysts were investigated based on $\mathrm{N}_{2}$ adsorption measurements. The $\mathrm{N}_{2}$ adsorption-desorption isotherms and their corresponding pore size distributions are shown in Fig. 2, and the relative structural parameters are summarized in Table 1. As shown in Fig.2(a), all samples exhibited typical type IV isotherms, as expected for common mesoporous silica; however, they possessed variation in their capillary condensation steps. Only one obvious capillary condensation step in the region of $p / p_{0}$ 0.3-0.45 is observed for the Pd/BMS-30 sample, suggesting that this support is largely composed of a single mesoporous structure (Fig. 2(b)). For the other samples, two capillary condensation steps are clearly observed in the $p / p_{0}$ regions of 0.4-0.75 and 0.8-0.95, respectively, indicating the presence of a bimodal mesopore. As indicated in the pore size distribution (Fig. 2(b)), the distribution of the textural mesopores is concentrated in the range of 18-45 $\mathrm{nm}$. In addition, all samples had a high specific surface area greater than $1000 \mathrm{~m}^{2} / \mathrm{g}$ and no significant differences in the specific surface area and total pore
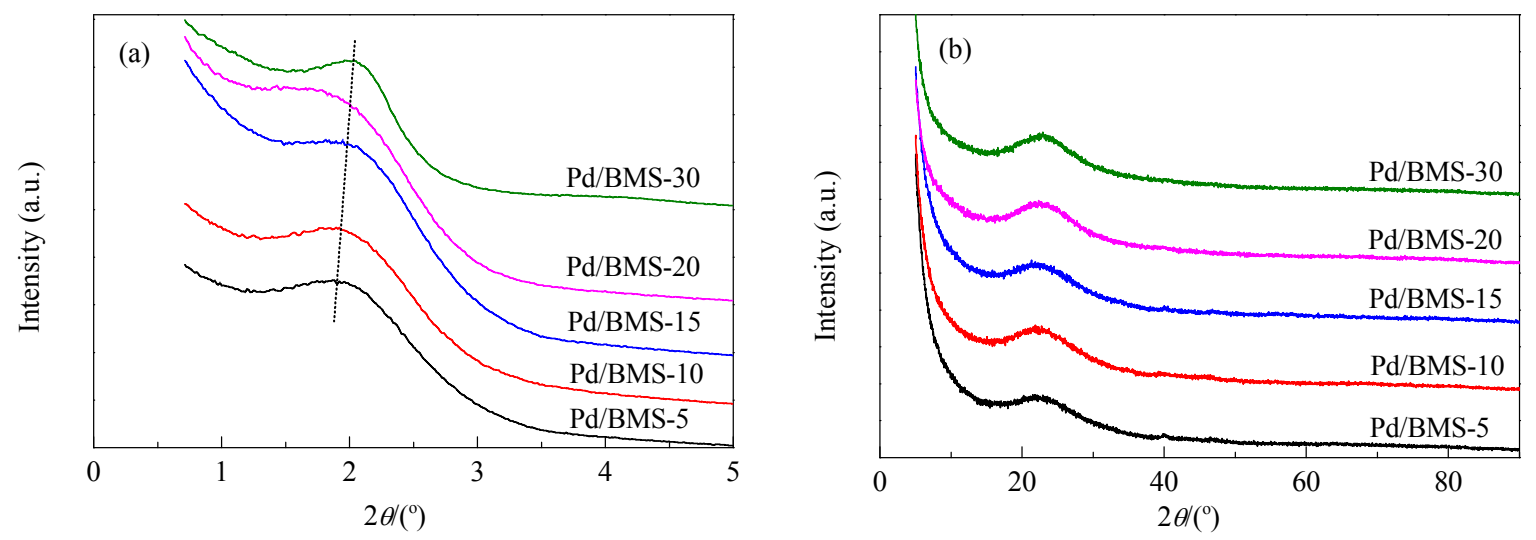

Fig.1. Small-angle (a) and wide-angle (b) XRD diffraction patterns of Pd/BMS- $x$ catalysts.
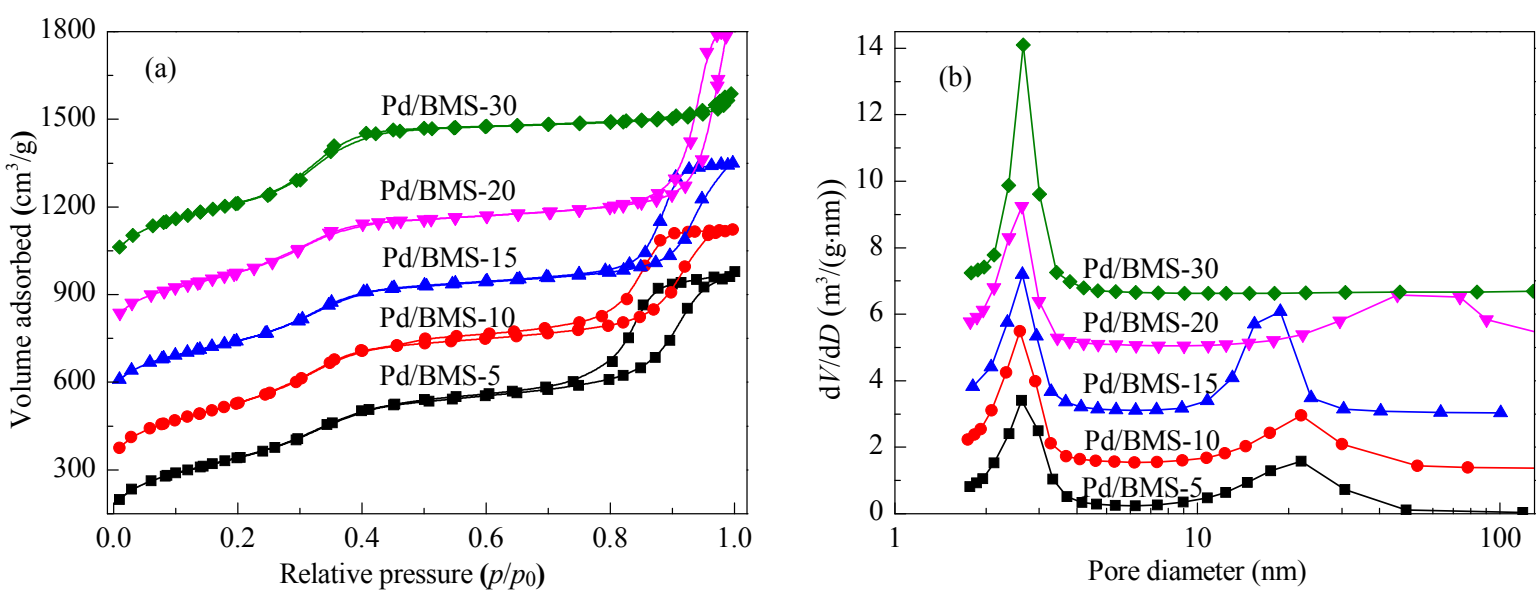

Fig. 2. $\mathrm{N}_{2}$ adsorption-desorption isotherms (a) and pore size distribution curves (b) of Pd/BMS- $x$ catalysts. 
Table 1

Physical and textural properties of Pd/BMS- $x$ catalysts.

\begin{tabular}{|c|c|c|c|c|c|c|}
\hline Catalyst & $\begin{array}{c}S_{\mathrm{BET}}{ }^{\mathrm{a}} \\
\left(\mathrm{m}^{2} / \mathrm{g}\right)\end{array}$ & $\begin{array}{c}V_{\mathrm{p}} \mathrm{b} \\
\left(\mathrm{cm}^{3} / \mathrm{g}\right)\end{array}$ & $\begin{array}{c}D_{\mathrm{p}(\mathrm{smalll}){ }^{\mathrm{c}}} \\
(\mathrm{nm})\end{array}$ & $\begin{array}{c}D_{\mathrm{p}(\text { large }}{ }^{\mathrm{c}} \\
\text { (nm) }\end{array}$ & $\begin{array}{l}d_{100}{ }^{\mathrm{d}} \\
(\mathrm{nm})\end{array}$ & $\begin{array}{c}a_{0} \mathrm{e} \\
(\mathrm{nm})\end{array}$ \\
\hline Pd/BMS-5 & 1024 & 1.24 & 2.64 & 22.36 & 4.59 & 5.30 \\
\hline Pd/BMS-10 & 1112 & 1.25 & 2.64 & 22.36 & 4.53 & 5.23 \\
\hline Pd/BMS-15 & 1232 & 1.46 & 2.64 & 18.91 & 4.34 & 5.01 \\
\hline Pd/BMS-20 & 1145 & 1.72 & 2.64 & 45.29 & 4.43 & 5.12 \\
\hline Pd/BMS-30 & 1243 & 1.08 & 2.66 & - & 4.32 & 4.99 \\
\hline
\end{tabular}

${ }^{\mathrm{a} B E T}$ specific surface area calculated. ${ }^{\mathrm{b}}$ Total pore volume estimated at $p / p_{0}=0.99$. ${ }^{\mathrm{C}} \mathrm{BJH}$ pore diameter calculated from the desorption branch. $\mathrm{d}$ Interplanar spacing of the (100) plane from XRD. e Lattice parameter, $a_{0}=2 d_{100} / \sqrt{3}$.

volume were observed between samples (Table 1).

\subsection{Catalytic activity and stability tests}

The catalytic performances of the synthesized Pd/BMS- $x$ catalysts for toluene oxidation at a gas hourly space velocity (GHSV) of $42000 \mathrm{~h}^{-1}$ are shown in Fig. 3 and Table 2. In all tests, $\mathrm{CO}_{2}$ and $\mathrm{H}_{2} \mathrm{O}$ were found to be the only products, indicating that toluene can be completely oxidized over these catalysts. The Pd/BMS-5-Pd/BMS-20 catalysts, with a bimodal mesopore structure, clearly had a higher catalytic activity than the Pd/BMS-30 catalyst with only a unimodal mesopore structure for the total catalytic oxidation of toluene. The $T_{90}$ values (the reaction temperature at which toluene conversion was 90\%) on the Pd/BMS-5-Pd/BMS-20 catalysts was $\sim 240{ }^{\circ} \mathrm{C}$. At the same reaction temperature, the Pd/BMS-30 catalyst could only achieve a conversion of $\sim 22 \%$, demonstrating the important promotional role of the support pore structure in enhancing the catalytic performance. Among the bimodal mesoporous catalysts, Pd/BMS-15 produced a slightly better performance, with a $T_{90}$ of $228^{\circ} \mathrm{C}$ for the oxidation of toluene.

The catalytic stability of Pd/BMS-15 was further tested at $250{ }^{\circ} \mathrm{C}$ for $60 \mathrm{~h}$, and the result is shown in Fig. 4. No significant deactivation in catalytic activity was observed within $60 \mathrm{~h}$ during the on-stream reaction experiments. In addition, the XRD pattern of the used Pd/BMS-15 catalyst was similar to that of the fresh one. No noticeable decrease was observed in the specific surface area $\left(1019 \mathrm{~m}^{2} / \mathrm{g}\right)$ of the used catalysts. With re-

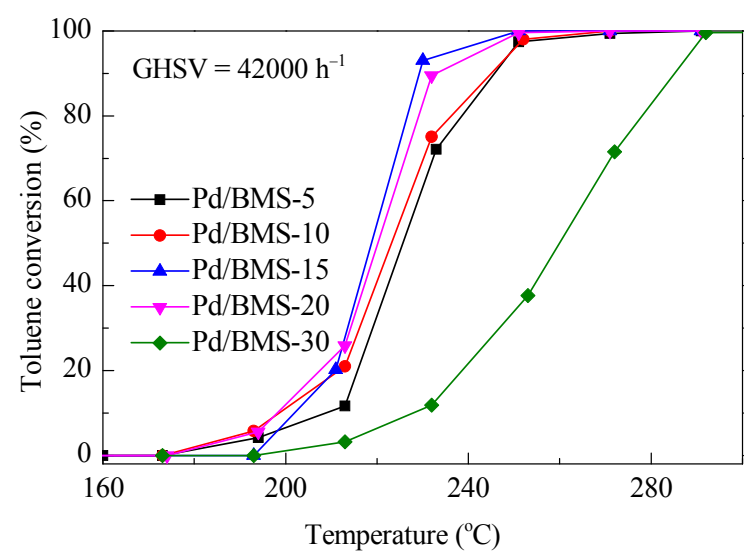

Fig. 3. Conversion profiles of toluene catalytic oxidation over Pd/BMS- $x$ catalysts.
Table 2

Properties and catalytic performances of Pd/BMS-x catalysts.

\begin{tabular}{lcccc}
\hline \multirow{2}{*}{ Catalyst } & $\begin{array}{c}\text { Pd loadinga } \\
\text { (wt\%) }\end{array}$ & $\begin{array}{c}\text { Dispersion } \\
\text { b }\end{array}$ & \multicolumn{2}{c}{ Toluene oxidation } \\
\cline { 4 - 5 } & 0.30 & 41 & $T_{50} \mathrm{c}\left({ }^{\circ} \mathrm{C}\right)$ & $T_{90}{ }^{\mathrm{c}}\left({ }^{\circ} \mathrm{C}\right)$ \\
\hline Pd/BMS-5 & 0.34 & 41 & 226 & 247 \\
Pd/BMS-10 & 0.41 & 69 & 223 & 246 \\
Pd/BMS-15 & 0.45 & 39 & 220 & 228 \\
Pd/BMS-20 & 0.35 & 27 & 259 & 286 \\
\hline Pd/BMS-30 & 0.40 & 238 \\
\hline
\end{tabular}

a Pd actual content of samples determined by ICP-OES (wt\%).

${ }^{\mathrm{b}}$ Dispersion estimated from $\mathrm{CO}$ chemisorptions.

c Temperatures at which $50 \%$ and $90 \%$ conversion of toluene.

gard to porosity, used catalysts still maintained bimodal mesoporous structure characteristics. These results demonstrate that the Pd/BMS-15 catalyst was catalytically stable.

\subsection{TEM and FE-SEM images of catalysts}

Figures 5 and 6 show the SEM and TEM images of BMS-15 and BMS-30 supports and the corresponding Pd/BMS-15 and Pd/BMS-30 catalysts. The SEM images (Fig5. 5(a, b)) clearly show that BMS-15 support contains disordered sponge-like large mesoporous channels. TEM images (Fig. 5(c, d)) further show the coexistence of a bimodal mesoporous structure and illustrates that the formation of large mesoporous channels was mainly because of the packing of primary particles. Nevertheless, the BMS-30 support had a distinctly different morphology from the BMS-15 support, with particle-stacking characteristics (Fig. 5(e)) and the corresponding particle size also had a broad distribution (Fig. 5(f, g)).

For the Pd/BMS-15 catalyst, Pd nanoparticles with a uniform size and high density were homogeneously deposited on the BMS-15 support and no larger agglomerated particles were observed (Fig. 6(a, b)). The size of the supported Pd nanoparticles was $\sim 3 \mathrm{~nm}$ on average. However, Pd nanoparticles displayed a different dispersion behavior on the Pd/BMS-30 catalyst. Irregular and relatively large particles were present on the BMS-30 support and the agglomeration of Pd particles is clearly discernable (Fig. 6c, d). Moreover, the Pd nanoparticles were significantly larger for Pd/BMS-30 ( 8-17 nm) than Pd/BMS-15.

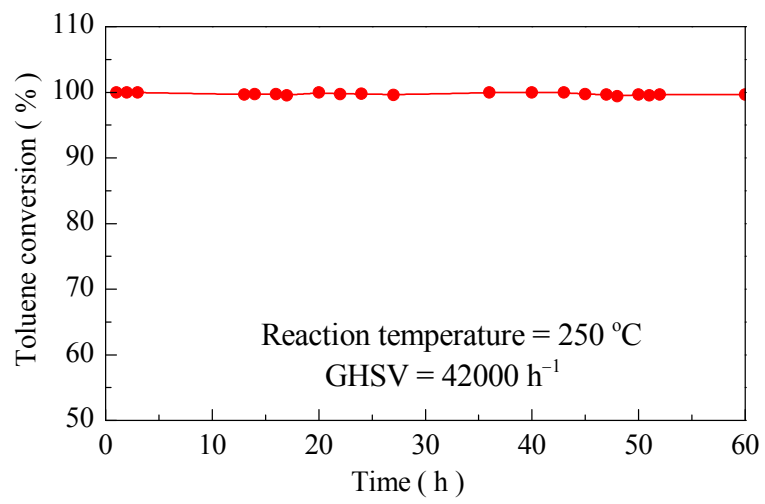

Fig. 4. Stability test for toluene catalytic oxidation over Pd/BMS-15 catalyst. 

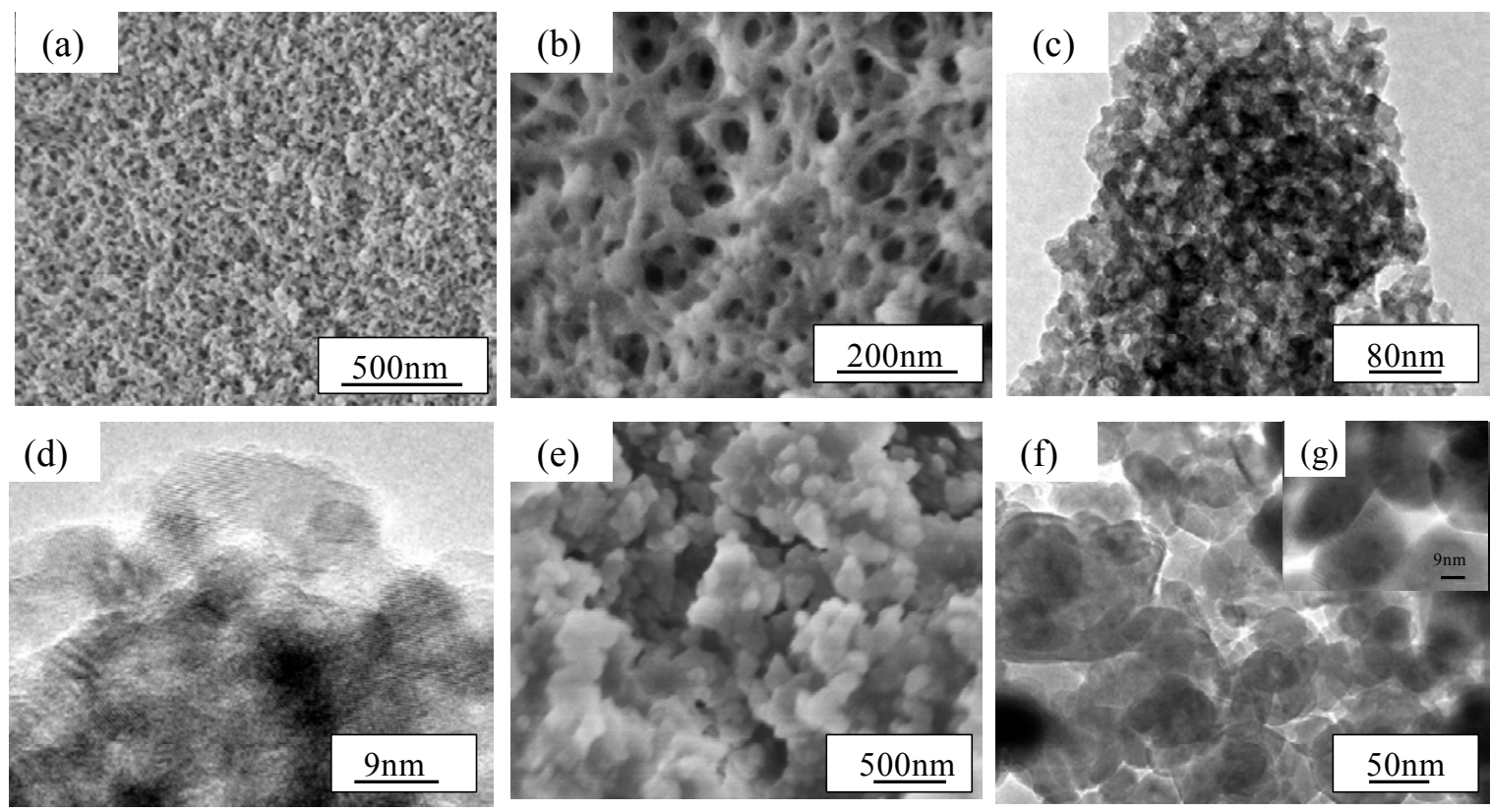

Fig.5. SEM and TEM images of BMS-15 (a-d) and BMS-30 (e-g) supports.

\subsection{Pd dispersion in catalysts}

Pd dispersion was determined by CO chemisorption and the results are summarized in Table 2 . The Pd/BMS-30 catalyst had a relatively low Pd dispersion (27\%), while Pd/BMS-5-Pd/ BMS-20 catalysts had dramatically improved Pd dispersion (39\%-69\%). The Pd/BMS-15 catalyst had the highest Pd dispersion (69\%). In most cases, the specific surface area of the support is recognized as the crucial factor in metal dispersion. Moreover, metal dispersion has been reported to be closely related to the support structure [31,32]. Therefore, although having the highest specific surface area, the BMS-30 support with a unimodal mesopore structure still hinders uniform distribution of Pd during impregnation and suffers from sintering when subjected to subsequent thermochemical processing
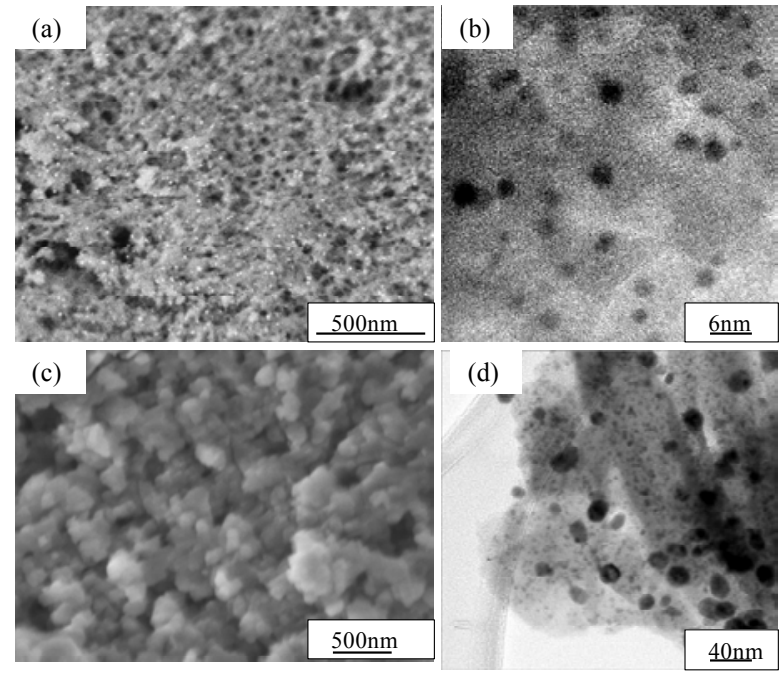

Fig. 6. SEM and TEM images of the Pd/BMS-15 (a,b) and Pd/BMS-30 (c,d) catalysts.
[33]. Such factors are unfavorable for the dispersion of Pd particles. In contrast, the bimodal mesoporous structure supports provide both high surface area and pore volume sufficiently to enhance uniformity of the Pd precursor throughout the mesopore channels, limiting migration and agglomeration of the $\mathrm{Pd}$ nanoparticles. Clearly, increasing the dispersion of the Pd species exposes toluene to more $\mathrm{Pd}$ sites on the catalyst and therefore significantly improves catalytic activity.

\subsection{Comparison of the catalytic performance of Pd/MCM catalysts}

The catalytic activity of the Pd/MCM-41 and Pd/MCM-48 catalysts (their textural properties are shown in Fig. 7) was further evaluated and compared with that of Pd/BMS-15, and the results are shown in Fig. 8. Under a GHSV of $42000 \mathrm{~h}^{-1}$, all three catalysts had a similar catalytic activity, with $90 \%$ toluene conversion at $225-230{ }^{\circ} \mathrm{C}$ (Fig. 8(a)). However, after increasing the GHSV to $70000 \mathrm{~h}^{-1}, \mathrm{Pd} / \mathrm{BMS}-15$ exhibited a remarkably higher catalytic activity than the Pd/MCM-41 and Pd/MCM-48 catalysts, as shown in Fig. 8(b). The $T_{90}$ over Pd/BMS-15 was $230{ }^{\circ} \mathrm{C}$-an insignificant increase compared with the $T_{90}$ value at a GHSV of $42000 \mathrm{~h}^{-1}$. The catalytic activity of Pd/MCM-41 and Pd/MCM-48 clearly decreased at a GHSV of $70000 \mathrm{~h}^{-1}$, with $T_{90}$ increasing by 23 and $39^{\circ} \mathrm{C}$, respectively.

To examine the effect of water vapor on catalytic activity, 11 vol\% of water vapor was introduced to the reaction system. As shown in Fig. 9, the introduction of water vapor at $250{ }^{\circ} \mathrm{C}$ under a GHSV of $42000 \mathrm{~h}^{-1}$ had dramatic effects on the catalytic performance among the three catalysts. For the Pd/MCM-41 and $\mathrm{Pd} / \mathrm{MCM}-48$ catalysts, the conversion of toluene decreased by $14 \%$ and $9 \%$ respectively, while the catalytic activity of Pd/BMS-15 remained stable-the conversion of toluene remained at $99 \%$ during the 500 min on-stream reaction experi- 

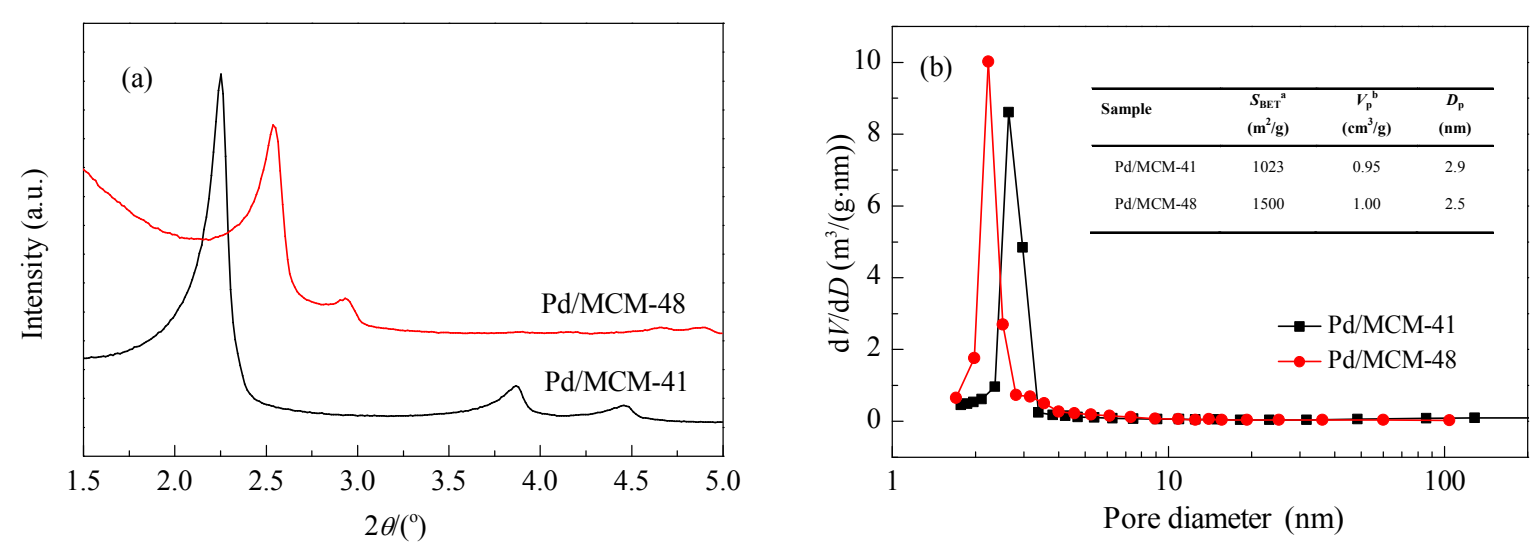

Fig. 7. XRD patterns (a) and $\mathrm{N}_{2}$ adsorption-desorption isotherms (b) of Pd/MCM-41 and Pd/MCM-48.
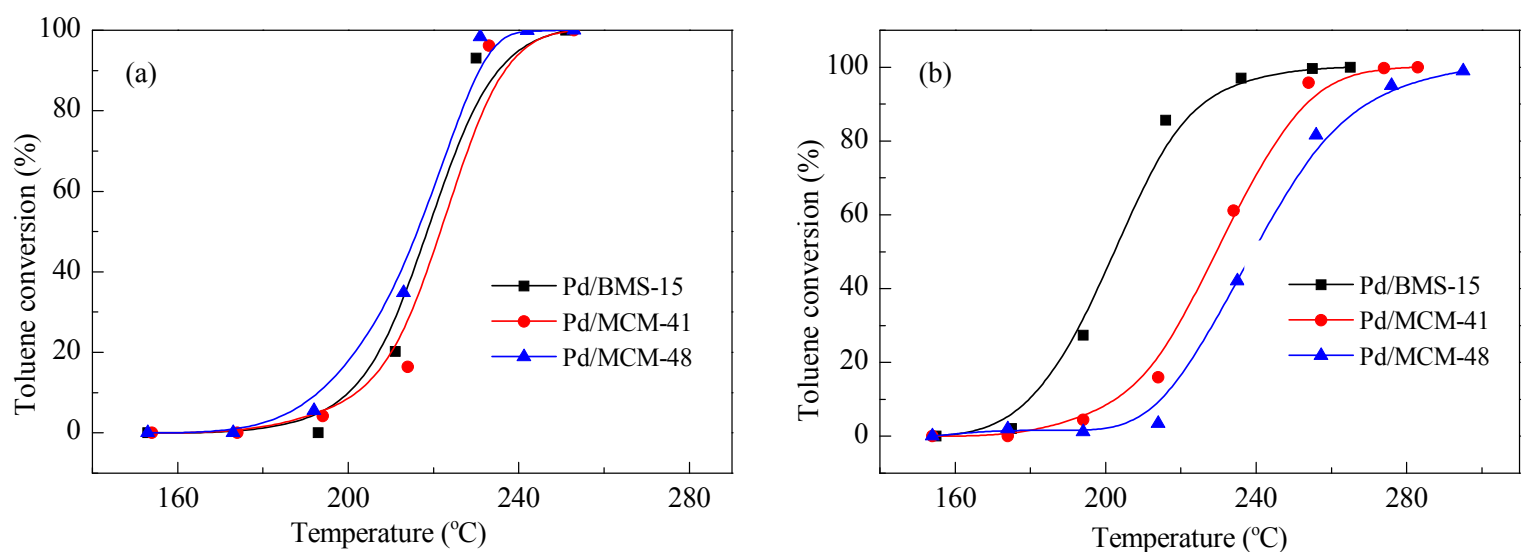

Fig. 8. Conversion profiles of toluene catalytic oxidation over Pd/MCM-41, Pd/MCM-48 and Pd/BMS-15 at different GHSV: (a) GHSV = 42000 h ${ }^{-1}$; (b) GHSV $=70000 \mathrm{~h}^{-1}$.

ments. In the presence of water vapor, a competitive adsorption of water vapor, toluene and oxygen molecules occurred on the surface of the catalyst. In relation to the Pd/MCM-41 and Pd/MCM-48 catalysts, toluene and oxygen molecules experience diffusion limitations when attempting to access the pores in the presence of a large amount of water vapor than for Pd/BMS-15, with its unique bimodal mesoporous structure. Furthermore, the continual decrease of catalytic activity of

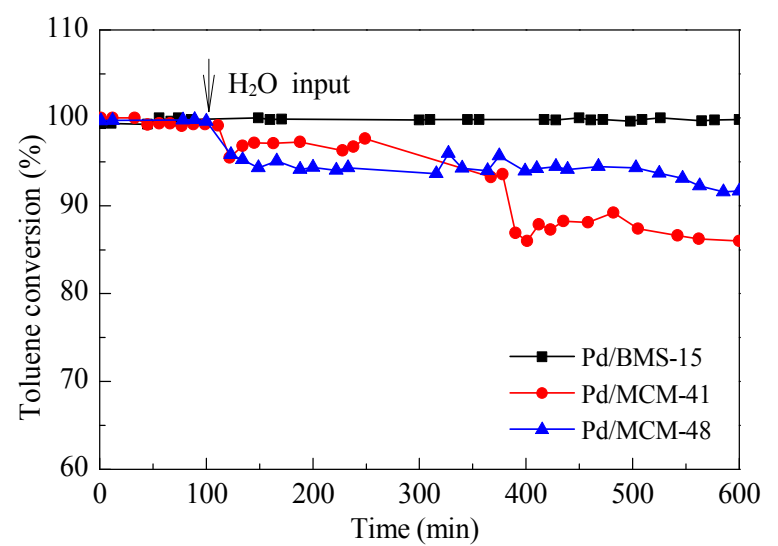

Fig. 9. Effect of water vapor on toluene catalytic oxidation over Pd/MCM-41, Pd/MCM-48 and Pd/BMS-15. Reaction conditions: $250^{\circ} \mathrm{C}$, $42000 \mathrm{~h}^{-1}, 11$ vol $\% \mathrm{H}_{2} \mathrm{O}$.
Pd/MCM-41 and Pd/MCM-48 catalysts could be attributed to the collapse of MCMs structure.

\subsection{Discussion}

3.6.1. Mechanism for the synthesis of bimodal mesoporous silica

The formation mechanism of the bimodal mesoporous silica can be simplified as follows. TEOS was first hydrolyzed to form monomeric and oligomeric silicate anions. The surfactant head group of the CTA micelle (positively charged) and the monomeric/oligomeric silicate ions (negatively charged) interact to form a micelle-encapsulated silica cluster. These micelle-encapsulated silica clusters react with existing adjacent particles to finally form a bridged interconnected textural mesostructure. The variation in the textural mesoporosity of samples is related to the relative rates of hydrolysis and condensation of TEOS, which influenced the size and packing geometry of the primary silica particles. Increasing the ammonia/silica molar ratio increases the hydrolysis and condensation rates accordingly resulting in the formation of larger silica primary particles, loosely bridged to other primary particles forming a larger textural porosity. From the $\mathrm{N}_{2}$ adsorption-desorption isotherms of the Pd/BMS-5-Pd/BMS-20 catalysts, the first step in the $p / p_{0}$ region of $0.4-0.75$ could be related to the capillary condensation of $\mathrm{N}_{2}$ inside the intraparticle 
mesopores belonging to the typical surfactant-templated silica materials. The pores, with a diameter of $\sim 2.6 \mathrm{~nm}$, were predominantly constructed with negatively charged silicates and positively charged CTA micelles. The second sharp step, at a high relative pressure $\left(p / p_{0}>0.8\right)$, implies the coexistence of textural mesopores, corresponding to the filling of the interparticle spaces among the nanoparticles. The secondary pore size was highly dependent on the rate of hydrolysis and condensation of TEOS and was mainly controlled by the ammonia/silica molar ratio [28,34]. As shown in Table 1, the size of textural mesopores changed from 18 to $30 \mathrm{~nm}$ with an increase in the ammonia/silica molar ratio.

\subsubsection{Effect of the catalyst structure on catalytic performance}

The oxidation of VOCs is a typical gas-solid catalysis reaction, which takes place at the interface boundary of the solid catalyst and gas reactants $\left(\mathrm{O}_{2}\right.$, VOCs). In a typical gas-solid catalysis reaction, five steps are necessary: (1) external diffusion of reactants, (2) internal diffusion of reactants, (3) surface reaction and the formation of products, (4) internal diffusion of products and (5) external diffusion of products. During the whole process, the catalytic efficiency of the catalyst is strongly influenced by the structure and physical state of the catalysts. As the structural characteristics affect the dispersion of the active phase, $\mathrm{Pd}$, determining molecular mobility is important to assess the diffusion of reactants and products. Therefore, in contrast to the Pd/BMS-30 catalyst, the reason that the bimodal mesopore catalysts have a higher catalytic activity is that they possess uniform intraparticle mesoporosity in addition to interconnected sponge-like interparticle mesoporous channels. This unique structure can facilitate the fast diffusion and transport of reactants and products, which reduces the diffusion limitations of reactants to the inner surface of the catalyst and increases the accessibility of the reactants to the active sites $[33,35]$. Under the higher GHSV, the diffusion of reactants and products on the catalyst was the main factor that deter- mined the catalytic performance [36], which explains the excellent performance of Pd/BMS-15 compared with Pd/MCMs in the catalytic oxidation of toluene at the higher GHSV.

\section{Conclusions}

A series of bimodal mesoporous silica (BMS- $x$ )-supported Pd catalysts were successfully synthesized. The synthesized catalysts possessed a bimodal mesopore distribution, including an intraparticle framework mesopore $(\sim 2.6 \mathrm{~nm})$ and interparticle textural mesopore (18-40 nm). This unique bimodal structure had a significant effect on their catalytic performance. The Pd/BMS-15 catalyst exhibited enhanced performance in the oxidation of toluene, with a $T_{90}$ of $228^{\circ} \mathrm{C}$. Compared with the Pd/MCM-41 and Pd/MCM-48 catalysts, Pd/BMS-15 displayed improved hydrothermal stability and catalytic performance at a high GHSV of $70000 \mathrm{~h}^{-1}$. The superior catalytic activity was mainly related to the enhanced uniform dispersion of the active Pd species together with increased diffusion of reactants and products.

\section{References}

[1] Taylor M N, Zhou W, Garcia T, Solsona B, Carley A F, Kiely C J, Taylor S H.J Catal, 2012, 285: 103

[2] Zhu Z Z, Lu G Z, Zhang Z G, Guo Y, Guo Y L, Wang Y Q. ACS Catal, 2013, 3: 1154

[3] Wu Y S, Zhang Y X, Liu M, Ma Z C. Catal Today, 2010, 153: 170

[4] Li J J, Xu X Y, Jiang Z, Hao Z P, Hu C. Environ Sci Technol, 2004, 39 : 1319

[5] Wang F, Dai H X, Deng J G, Bai G M, Ji K M, Liu Y X. Environ Sci Technol, 2012, 46: 4034

[6] Zhan W C, Guo Y, Gong X Q Guo Y L, Wang Y Q Lu G Z. Chin J Catal (詹望成, 郭耘, 龚学庆, 郭杨龙, 王艳芹, 卢冠忠. 催化学报), 2014, 35: 1238

[7] Garcia T, Solsona B, Murphy D M, Antcliff K L, Taylor S H. J Catal, 2005, 229: 1

\section{Graphical Abstract}

Chin. J. Catal., 2015, 36: 1686-1693 doi: 10.1016/S1872-2067(15)60924-X

High performance Pd catalysts supported on bimodal mesopore silica for the catalytic oxidation of toluene

Nanli Qiao, Yang Li, Na Li, Xin Zhang, Jie Cheng*, Zhengping Hao

Research Center for Eco-Environmental Sciences, Chinese Academy of Sciences
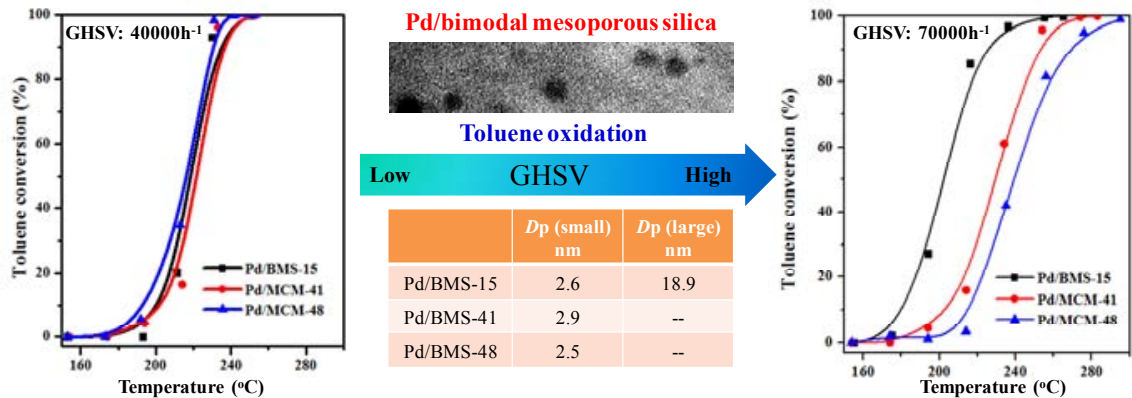

Bimodal mesoporous silica supported Pd catalysts showed high activity and stability for the catalytic oxidation of toluene under high gas hourly space velocity making these catalysts promising for elimination of volatile organic compounds. 
[8] Garcia T, Solsona B, Cazorla-Amorós D, Linares-Solano Á, Taylor S H. Appl Catal B, 2006, 62: 66

[9] He C, Zhang X Y, Cao S K, Chen J S, Hao Z P. J Ind Eng Chem, 2012, 18: 1598

[10] Li W B, Zhuang M, Xiao T C, Green M L H.J Phys Chem B, 2006, 110: 21568

[11] He C, Li J J, Cheng J, Li L D, Li P, Hao Z P, Xu Z P. Ind Eng Chem Res, 2009, 48: 6930

[12] He C, Li J J, Li P, Cheng J, Hao Z P, Xu Z P. Appl Catal B, 2010, 96: 466

[13] Fechete I, Ersen O, Garin F, Lazar L, Rach A. Catal Sci Technol, 2013, 3: 444

[14] Oh C G, Baek Y, Ihm S K. Adv Mater, 2005, 17: 270

[15] Dhainaut J, Dacquin J P, Lee L A, Wilson K. Green Chem, 2010, 12 : 296

[16] Holland B T, Abrams L, Stein A. J Am Chem Soc, 1999, 121: 4308

[17] Zhang Y, Yoneyama Y, Tsubaki N. Chem Commun, 2002: 1216

[18] Liu X M, Xue H X, Li X, Yan Z F. Catal Today, 2010, 158: 446

[19] Li X, Han D Z, Xu Y Q, Liu X M, Yan Z F. Mater Lett, 2011, 65: 1765

[20] Gheorghiu S, Coppens M O. AIChE J, 2004, 50: 812

[21] Sato S, Takahashi R, Sodesawa T, Koubata M. Appl Catal A, 2005, 284: 247
[22] Takahashi R, Sato S, Sodesawa T, Arai K, Yabuki M. J Catal, 2005, 229: 24

[23] Zhang X J, Hirota R, Kubota T, Yoneyama Y, Tsubaki N. Catal Commun, 2011, 13: 44

[24] Chen X F, Wang X C, Fu X Z. Energy Environ Sci, 2009, 2: 872

[25] Kamperman M, Burns A, Weissgraeber R, Vegten N V, Warren S C, Gruner S M, Baiker A, Wiesner U. Nano Lett, 2009, 9: 2756

[26] Lu S H, Liu Y, Wang Y Q. Chem Commun, 2010, 46: 634

[27] Wang X Z, Dou T, Xiao Y Z. Chem Commun, 1998, 1035

[28] Wang X Z, Li W H, Zhu G S, Qiu S L, Zhao D Y, Zhong B. Microporous Mesoporous Mater, 2004, 71: 87

[29] Zhang B J, Davis S A, Mann S. Chem Mater, 2002, 14: 1369

[30] Yun J S, Ihm S K. J Phys Chem Solids, 2008, 69: 1133

[31] Parlett C M A, Keshwalla P, Wainwright S G, Bruce D W, Hondow N S, Wilson K, Lee A F. ACS Catal, 2013, 3: 2122

[32] Parlett C M A, Bruce D W, Hondow N S, Newton M A, Lee A. F, Wilson K. ChemCatChem, 2013, 5: 939

[33] Avinoam N, Leonid P M. Chem Eng Sci, 1977, 32: 35

[34] Ikari K, Suzuki K, Imai H. Langmuir, 2004, 20: 11504

[35] Leitão A, Rodrigues A. Chem Eng J Biochem Eng J, 1995, 60: 111

[36] Wang F, Li J S, Yuan J F, Sun X Y, Shen J Y, Han W Q, Wang L J. Catal Commun, 2011, 12:1415

\title{
双介孔硅基材料负载Pd催化剂上甲苯氧化性能的研究
}

\author{
乔南利, 李 杨, 李 娜, 张 金金, 程 杰”, 郝郑平 \\ 中国科学院生态环境研究中心, 北京 100085
}

摘要: 催化氧化技术是挥发性有机物(VOCs)减排与控制的主流技术之一, 其关键之处在于高效催化材料的研究与开发, 负载型贵金 属催化材料由于其低温下优越的VOCs催化氧化性能, 受到国内外研究者的广泛关注. 对于负载型催化剂而言, 载体的性质直接影响 活性相的分散, 反应物和生成物的扩散与吸脱附, 是影响负载型催化剂性能的主要因素. 近年来, 多级孔结构硅基材料由于具有多级 的孔道结构、高比表面积和大的孔体积, 逐渐成为VOCs催化氧化材料的研究热点.

本文采用溶胶凝胶法和浸渍法制备了系列双介孔结构硅基材料负载Pd催化剂(Pd/BMS- $x$ ), 通过控制合成过程中氨水的用量以调 节催化剂的介孔结构分布. X射线衍射(XRD)结果表明, 所合成的Pd/BMS- $x$ 催化剂在 $2.0^{\circ}$ 的衍射峰, 类似于MCM- 41 的 (100)晶面 衍射峰, 表明所有的样品均具有有序的介孔结构. $\mathrm{N}_{2}$ 吸脱附实验表明所有样品的比表面积均高于 $1000 \mathrm{~m}^{2} / \mathrm{g}$, 孔径分布表明 Pd/BMS-30样品为单一介孔结构, 而Pd/BMS-5 Pd/BMS-20样品具有 $2.64 \mathrm{~nm}$ 以及 $18-45 \mathrm{~nm}$ 范围内的双介孔结构, 且 Pd/BMS-15样 品介孔分布较为集中. Pd/BMS- $x$ 催化剂上甲苯催化氧化性能测试表明, 双介孔结构的Pd/BMS-5 Pd/BMS-20催化剂上甲苯催化氧 化活性远高于单一介孔结构的Pd/BMS-30催化剂, 表明载体结构对催化剂性能有重要影响. 其中, Pd/BMS-15催化剂性能最佳 $\left(T_{90}\right.$ 为 $228^{\circ} \mathrm{C}$ )且具有较强的稳定性, $250^{\circ} \mathrm{C}$ 条件下, 反应持续 $60 \mathrm{~h}$ 催化剂未见明显失活. SEM和TEM结果表明, Pd/BMS-15催化剂中Pd 高度分散于载体上, 平均粒径在 $3 \mathrm{~nm}$ 左右. 而Pd/BMS-30催化剂中Pd颗粒间有明显的团聚, 平均粒径在 $8 \sim 17 \mathrm{~nm}$ 之间. 分散度测 试表明, 单一介孔结构的Pd/BMS-30催化剂, Pd分散度仅为 $27 \%$, 而双介孔结构 Pd/BMS-5-Pd/BMS-20催化剂介于 $39 \%$ 到 $69 \%$, 其中 Pd/BMS-15催化剂中Pd分散度高达69\%.

与常规单一介孔MCM-41和MCM-48负载Pd催化剂相比, 在低空速 $\left(42000 \mathrm{~h}^{-1}\right)$ 条件下, Pd/BMS-15催化剂上甲苯催化氧化性能 与 Pd/MCM-41和Pd/MCM-48催化剂相当. 高空速 $\left(70000 \mathrm{~h}^{-1}\right)$ 条件下, Pd/BMS-15催化剂的活性远高于单一介孔的Pd/MCM-41和 Pd/MCM-48催化剂. Pd/BMS-15催化剂独特的双介孔结构, 有利于活性相Pd的分散、反应物的扩散和传输, 特别是在高空速条件 下, 有利于反应物与活性相的接触, 提高了材料的氧化反应性能. 进一步考察了材料的水热稳定性, 将 $11 \mathrm{vol} \%$ 的水蒸气引入到反 应体系中, 测试结果表明水蒸气的加入导致Pd/MCM-41和Pd/MCM-48催化剂的甲苯催化氧化性能显著下降, 反应500 min后甲苯 转化率分别从 $100 \%$ 下降到 $76 \%$ 和 $81 \%$, 而对于Pd/BMS- 15 催化剂, 水蒸气的引入并未导致其活性明显下降, 从而表明Pd/BMS-15催 化材料具有较高的水热稳定性.

关键词: 双介孔硅; 孔结构; 催化氧化; 甲苯; 钯

收稿日期: 2015-03-16. 接受日期: 2015-06-11. 出版日期: 2015-10-20.

*通讯联系人. 电话/传真: (010)62843688; 电子信箱: jiecheng@rcees.ac.cn

基金来源：国家自然科学基金(21337003, 21477149); 中国科学院战略性先导科技专项(XDB05050200).

本文的英文电子版由Elsevier出版社在ScienceDirect上出版(http://www.sciencedirect.com/science/journal/18722067). 